\title{
The TLC Model of Palliative Care in the Elderly: Preliminary Application in the Assisted Living Setting
}

Antbony F. Jerant, $M D^{1}$

Rabman S. Azari, PbD ${ }^{2}$

Thomas S. Nesbitt, MD, MPH

Frederick J. Meyers, $M D^{3}$

'Department of Family and Community Medicine, University of California Davis School of Medicine, Sacramento, Calif

${ }^{2}$ Department of Statistics, University of California Davis School of Medicine, Sacramento, Calif

${ }^{3}$ Department of Internal Medicine, University of California Davis School of Medicine, Sacramento, Calif

Conflict of interest: none reported

\section{CORRESPONDING AUTHOR}

Anthony F. Jerant, MD

Department of Family and Community Medicine

University of California Davis School of

Medicine

4860 Y Street, Suite 2300

Sacramento, CA 95817

afjerant@ucdavis.edu

\begin{abstract}
Substantial shortfalls in the quality of palliative care of the elderly can be attributed to 5 fundamental flaws in the way end-of-life care is currently delivered. First, palliative care is viewed as a terminal event rather than a longitudinal process, resulting in a reactive approach and unnecessary preterminal distress in elderly patients suffering from chronic, slowly progressive illnesses. Second, palliative care is defined in terms of a false dichotomy between symptomatic and disease-focused treatment, which distracts attention from the proper focus of healing illness. Third, the decision about whether the focus of care should be palliative is not negotiated among patients, family members, and providers. Fourth, patient autonomy in making treatment choices is accorded undue prominence relative to more salient patient choices, such as coming to terms with their place in the trajectory of chronic illness. Fifth, palliative care is a parallel system rather than an integrated primary care process. A new theoretical framework-the TLC modeladdresses these flaws in the provision of palliative care for elderly persons. In this model, optimal palliative care is envisioned as timely and team oriented, longitudinal, collaborative and comprehensive. The model is informed by the chronic illness care, shared decision making, and comprehensive geriatric assessment research literature, as well as previous palliative care research. Preliminary results of an intervention for elderly assisted living residents based on the TLC model support its promise as a framework for optimizing palliative care of elders.
\end{abstract}

Ann Fam Med 2004;2:54-60. DOI: 10.1370/afm.29.

\section{INTRODUCTION}

$\mathrm{D}$ espite ambitious palliative care research initiatives ${ }_{1}^{1}$ process improvement efforts, ${ }^{2}$ and education programs, ${ }^{3}$ the quality of palliative care provided to the elderly remains poor. Myriad studies have shown that many older persons nearing the end of life experience unnecessary suffering caused by uncontrolled symptoms, ${ }^{4-8}$ depression, ${ }^{9}$ such existential struggles as making sense of the meaning of one's life, ${ }^{10,11}$ and other issues. These shortfalls exist across a variety of care settings, ${ }^{12}$ including the community, ${ }^{8,9}$ nursing homes, ${ }^{6,7}$ and hospitals. ${ }^{4}$

There is a growing recognition ${ }^{3,13,14}$ that previous efforts have largely failed because the underlying conceptual framework for palliative care currently applied to the elderly is fundamentally flawed. We submit that palliative care in older patients should not be viewed as synonymous with hospice or end-of life-care. Rather, palliative care should be viewed as any care primarily intended to relieve the burden of physical and emotional suffering that often accompanies the illnesses associated with aging. Palliative care should thus be a major focus of care throughout the aging process, regardless of whether death is immediately proximate. With this approach, end-of-life care, regardless of whether provided within a hospice framework, represents only part of the continuum of longitudinal palliative care (Figure 1). 
The purposes of this article are (1) to review the problems with the prevailing model of palliative care for older persons, (2) to describe a new model-the TLC model - that provides a useful framework for addressing these problems, and (3) to describe an ongoing palliative care improvement intervention study based on the TLC model and how early results of the study support and inform the model.

\section{FUNDAMENTAL PROBLEMS WITH CURRENT PALLIATIVE CARE FOR THE ELDERLY}

\section{Palliative Care as a Terminal Event Rather Than a Longitudinal Process}

An unintended consequence of the hospice movement is the tendency to defer palliative care until patients are unequivocally dying. The 6-months-or-less life expectancy requirement for hospice eligibility ${ }^{15}$ compounds the problem. Whereas the hospice-based palliative care model is often applicable to younger patients dying of cancer, for whom the disease course is relatively predictable, it is ill suited to older persons. Older patients typically die of chronic, slowly progressive illnesses characterized by multiple acute episodes, often followed by full or partial recovery. Current prognostic models fail to accurately predict the timing of death from such illnesses. ${ }^{1,16,17}$ This fundamental mismatch between care paradigm and clinical reality has resulted in an approach to palliative care in the elderly characterized by reacting to acute exacerbation of chronic illness. The result is missed opportunities for palliation at all points along the chronic disease trajectory (Figure 1). Such missed opportunities are evidenced by the palliative care shortfalls mentioned previously, ${ }^{4-11}$ as well as the phenomenon of late hospice referrals resulting in very short lengths of stay in many programs. ${ }^{18}$

\section{Figure 1 . The palliative care continuum.}

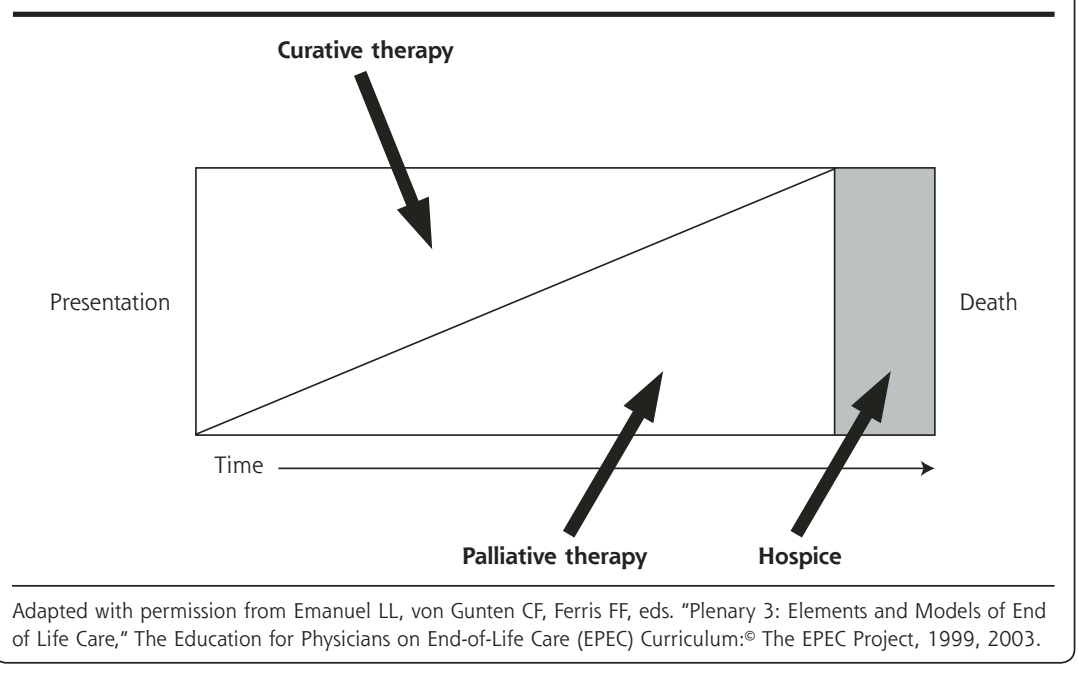

Palliative Care Defined Within a False Dichotomy of Symptomatic and Disease-Focused Treatment Because a disease is "a disorder with a specific cause and recognizable signs and symptoms,"19 the widely promulgated symptom-disease dichotomy is nonsensical. Furthermore, treating underlying disease processes also often ameliorates symptoms. Most importantly, this false dichotomy diverts attention from the proper focus of end-of-life care: the healing of illness, "the patient's personal experience of a physical or psychological disturbance." ${ }^{120}$ Symptoms often have no clear basis in objective disease, and one cannot generally palliate symptoms related to existential suffering (eg, coming to closure with loved ones) with disease-focused treatment.

We submit that only treatment intent helps to distinguish palliative care from other forms of medical care. Most current medical care seeks to prevent death. By contrast, in palliative care, illness is treated to maintain or slow the rate of decline in quality of life. ${ }^{21}$ The practical importance of the distinction is that treatment intent strongly influences the actual interventions chosen, as well as their extent, dose, and scheduling. For example, chemotherapy regimens for advanced cancer might or might not extend life, but essentially all such regimens cause side effects that can reduce quality of life. By contrast, palliative care might have less chance of extending life but is associated with far less toxicity and may actually lead to improved quality of life.

\section{Decision to Focus Care as Palliative Not Explicitly Negotiated}

In clinical practice, neither patients nor family members nor health care providers unilaterally determine treatment intent. Rather, a negotiated agreement among physicians, patients, and family members determines the balance between palliative and curative treatment in the present and future (Figure 1). ${ }^{22-24}$ In current care processes, such negotiation is generally tacit rather than explicit. In one study, ${ }^{25}$ family members of dying patients noted problems communicating with health care clinicians as a critical issue. In a second study, ${ }^{26}$ families noted that having adequate information and professional caregivers facilitate care transitions enhanced their chances of reaching a turning point at which death was viewed as imminent and helped them make informed decisions.

The current lack of explicit negotiation between patients and 
physicians regarding optimal balancing of palliative and curative treatment contributes to the neglect of existential patient suffering. ${ }^{10,22}$ Such issues as maintenance of dignity are often as important or more important to patients than symptoms such as pain. ${ }^{27}$ Lack of explicit negotiation also results in failure to support patients in coping with difficult issues early in the dying process, such as deciding where to live, learning to manage decreased finances, ${ }^{28}$ and struggling "to remain engaged in the everydayness that gives life meaning. ${ }^{29}$ Given the often long trajectory of decline in older patients with chronic illnesses, a palliative care approach that includes both managing remaining life and dealing with approaching death seems especially germane.

\section{Autonomous Patient Treatment Decisions Accorded Undue Prominence}

The current approach to palliative care is predicated on the false assumption that autonomy forms the basis of human dignity. ${ }^{30}$ In reality, palliative care choices are heavily dependent upon the presentation of choice by the physician. As noted previously, the difference between the ideal shared decision-making approach and the current one is that physician biases and preferences could be made explicit in the former, whereas in the latter they are generally hidden or implicit. Many treatment choices offered to patients in the name of honoring autonomy are in fact nonchoices. ${ }^{28}$ For example, dying patients are routinely asked whether they want invasive therapies to keep them alive even when there is no chance of survival, no matter what course is taken. The more salient or controlling choice noted by family caregivers of dying patients in one study was about "the perception of the person's stage in the illness trajectory" and resulting goals for quality of remaining life-factors that help to determine treatment intentand not primarily about which specific treatments were to be received. ${ }^{28}$

\section{Palliative Care as a Parallel System Rather Than an Integrated Process}

Palliative care presently occurs outside the usual care processes, often delivered by specialists and other personnel within the hospice framework, with little involvement from primary care physicians. Shoehorning prolonged palliative care discussions into already overloaded periodic office visits is unlikely to remedy this situation. Rather, for palliative care delivery to become an integral part of daily clinical practice, and to facilitate deeper, less hurried, longitudinal palliative care dialogues, creative new ways of maintaining continuous healing relationships ${ }^{31}$ among patients, families, and primary providers must be sought. Such relationships allow patients to receive care whenever and wherever they need it in a variety of forms, including face-to-face office visits, Internet and electronic mail communication, telephone calls, and other means.

\section{THE TLC MODEL OF PALLIATIVE CARE FOR THE ELDERLY}

To begin to remedy these problems, we propose the TLC model of palliative care for older patients (Table 1). In this model, palliative care is defined as care aimed at improving the quality of life of persons nearing (but not necessarily at) the end of life and facilitating the transitions before death. ${ }^{32}$ This increasingly endorsed definition, ${ }^{3,12,33,34}$ which contrasts with common usage of the term palliative care as a synonym for terminal care, does not simply arbitrarily extend the period before anticipated death. Rather, it acknowledges the prolonged process of nearing death faced by many older patients who have chronic illnesses and accounts for the wide variation in the point in time at which patients, families, and physicians perceive that death is approaching.

\section{T - Timely and Team Oriented}

Palliative care must be timely, not delayed in a misguided attempt to wait for a clearly terminal event, to avoid prolonged, unnecessary suffering. Furthermore, to achieve continuous healing relationships, palliative care must be team-oriented. Given the problem of competing demands during physician office visits, ${ }^{35}$ health care team members, such as nurses and trained lay persons, must play a major role in supporting family self-care efforts and implementing palliative care.

\section{L - Longitudinal}

The ideal trajectory of palliative care for the elderly is longitudinal, with an evolving balance of palliative and curative measures (Figure 1). ${ }^{3}$ Such an approach could overcome the current tendency to use a reactive approach to end-of-life care that is focused on acute 
illness exacerbation. Emerging concepts from the literature regarding interventions to optimize longitudinal chronic illness care ${ }^{31,36}$ can help to inform such a longitudinal approach.

\section{C - Collaborative and Comprehensive}

Palliative care must be a collaborative enterprise among physicians, patients, and their loved ones. Information should flow freely in all directions to facilitate shared decision making. The rich and growing body of literature concerning shared decision-making programs ${ }^{37,38}$ to help patients make health care decisions serves as a useful reference point. The content of palliative care efforts must also be comprehensive, informed by empirically supported domains of palliative care. ${ }^{3,39-42}$ Maintaining social roles and relieving existential suffering should be a particularly strong focus of palliative care for older patients to help maintain dignity throughout the dying process. ${ }^{23,43,44}$ The rich and comprehensive geriatric assessment ${ }^{45}$ research literature can help to inform the content of palliative care for older patients, even though the target population for the TLC approach is located close to (but not necessarily at) the hospice bar in Figure 1, whereas the target population for traditional comprehensive geriatric assessment is closer to the extreme left.

\section{PRELIMINARY EVALUATION OF THE TLC MODEL}

There is currently no empirical research to support the effectiveness of palliative care interventions based on the TLC model. Given its high face validity and grounding in descriptive research, however, we are conducting an evaluation of an intervention based on the TLC model. We describe the intervention and preliminary study findings in the following sections.

\section{Assisted Living: An Ideal Setting for TLC Model Application}

Assisted living facilities are congregate residential settings that provide or coordinate personal services, supervision, activities, and health-related services. ${ }^{46}$ There are about 1.5 million assisted living beds in the United States, and demand is expected to grow considerably during the next 20 years as the population ages. ${ }^{47}$ Three issues make the assisted living facility an ideal setting in which to evaluate the TLC model of palliative care for the elderly.

First, the elderly resident population is increasingly functionally impaired and frail. ${ }^{48,49}$ The typical resident is an 80-year-old woman who needs assistance with two activities of daily living. ${ }^{46}$ The estimated life expectancy for persons of this age and degree of frailty is generally less than 2 years. ${ }^{50}$ Thus, most elderly residents in assisted living facilities are nearing but not necessarily at the end of life. Second, because most residents suffer from multiple chronic illnesses for which an accurate prognosis is impossible, ${ }^{18,51}$ the current approach of delaying palliative care until death is clearly imminent is likely resulting in unnecessary, prolonged resident suffering. Third, recent reviews have disclosed no reports concerning palliative care needs or quality in this population. ${ }^{52,53}$

\section{The Palliative Care in Assisted Living (PCAL) Study}

To begin to fill this important knowledge gap and compare the effectiveness of 2 interventions for improving palliative care in older persons based on the TLC model, we are conducting the Palliative Care in Assisted Living (PCAL) study. From November 2000 through June 2004, English-speaking residents of 2 assisted living facilities in the Sacramento, Calif, area, operated by a single not-for-profit corporation, are being invited to volunteer for the PCAL study. Facility 1 houses 100 residents and facility 2 houses 35 residents. Care processes at the facilities are essentially identical. The average resident age is 85 years, two thirds are female, and nearly all are white and English speaking. Most residents pay facility fees out of pocket. Residents who cannot understand the consent form because of cognitive impairment or who are unable to consent because of serious acute illness are excluded.

\section{Methods}

The study is a nonblinded, prospective comparison trial. Intervention assignment is by facility to avoid cross-contamination among subjects. The study assessment (Table 2) combines a series of validated instruments to address content domains drawn from the palliative care ${ }^{3,39-42}$ and geriatric assessment ${ }^{45}$ literature. The assessment is conducted by one of the authors $(\mathrm{AFJ})$ at the facilities in 2 parts spaced 2 to 3 weeks apart, each lasting 1 to 1.5 hours. Nearly all the residents have at least 1 family member or friend who assists with making medical decisions, and whenever possible, we arrange for these persons to accompany the resident.

Within 24 hours of completing the assessment, a letter containing palliative care recommendations based on the findings (the study intervention), as well as resident and family input and preferences, is mailed to the resident, primary provider, and appropriate family member(s). Facility 1 (more intensive intervention) residents receive identical assessments with new recommendation letters every 3 months. For facility 2 (less intensive intervention) residents, outcomes are assessed at appointments every 3 
months, but no further recommendations are provided. Residents receive their assigned intervention until they leave their facility, die, or drop out.

Data regarding the impact of the ongoing study interventions on patient outcomes, such as healthrelated quality of life, are not yet available. We present, however, a brief summary of preliminary findings concerning the palliative care needs of enrollees. SPSS 10.0.5 for Windows (SPSS, Inc, Chicago, Ill) was used for all analyses.

\section{Preliminary Study Findings}

Sixty-one patients had enrolled by June 30, 2002: 44 at facility 1 ( $27 \%$ of the facility population since enrollment began) and 17 at facility 2 (28\% of the facility population). Data presented are for the 50 residents (facility $1, \mathrm{n}=37$, facility $2, \mathrm{n}=13$ ) who had received a baseline assessment before the interim analysis. Residents were very old (mean age 85.4 years, $\pm 7.2 \mathrm{SD}$ ), $36(72 \%)$ were female, $48(96 \%)$ were white $(96 \%)$ and highly educated, with a mean of $15.2( \pm 2.7 \mathrm{SD})$ years of formal education. Lack of energy $(27,54 \%)$, feeling drowsy $(27,54 \%)$, pain $(26,51 \%)$, feeling sad $(25$, $50 \%)$, difficulty concentrating $(25,50 \%)$, worrying (22,

\section{Table 2. Palliative Care in Assisted Living (PCAL) Study Assessment Elements and Measures}

\begin{tabular}{|c|c|}
\hline Element & Ascertainment and Measures \\
\hline \multicolumn{2}{|l|}{ Assessment part 1} \\
\hline Demographics & Discussion with resident, caregiver; review of facility records \\
\hline Diseases / diagnoses & $\begin{array}{l}\text { Discussion with resident, caregiver; review of facility records; } \\
\text { request records from primary care physician }\end{array}$ \\
\hline Medications & $\begin{array}{l}\text { Discussion with resident, caregiver; review of facility records; } \\
\text { request records from primary care physician }\end{array}$ \\
\hline Health status & $\begin{array}{l}\text { SF-36 Physical Component and Mental Component summary } \\
\text { scales }{ }^{54.56}\end{array}$ \\
\hline Symptoms & $\begin{array}{l}\text { Memorial Symptom Assessment Scale (MSAS) }{ }^{57} \text { items and } \\
\text { Global Distress Index (GDI) }\end{array}$ \\
\hline Hearing & Hand-held audiometer $(1,000 \text { and } 2,000 \mathrm{~Hz} \text { at } 40 \mathrm{~dB})^{45}$ \\
\hline Vision & Wall-mounted Snellen eye chart ${ }^{45}$ \\
\hline Mood & Geriatric Depression Scale, 15 -item ${ }^{58}$ \\
\hline Cognition & Mini Mental State Exam ${ }^{59}$ \\
\hline Activities of daily living & Self-report of mobility, toileting, transfers, eating ${ }^{60}$ \\
\hline Functional abilities & Physical Performance Test, 7 -item ${ }^{61}$ \\
\hline Balance & Performance oriented assessment of balance ${ }^{62}$ \\
\hline Gait & Performance oriented assessment of gait ${ }^{62}$ \\
\hline \multicolumn{2}{|l|}{ Assessment part 2} \\
\hline Social support & Social Support Survey ${ }^{63}$ \\
\hline Advance directives, current & Discussion with resident and caregiver; review of facility records \\
\hline $\begin{array}{l}\text { Medical decision-making } \\
\text { capacity }\end{array}$ & Clinical vignettes ${ }^{64}$ \\
\hline $\begin{array}{l}\text { Life values and goals for } \\
\text { medical care }\end{array}$ & Values History, modified ${ }^{65}$ \\
\hline $\begin{array}{l}\text { Wishes regarding aggressive } \\
\text { interventions }\end{array}$ & Values History, modified ${ }^{65}$ \\
\hline Hospice eligibility & $\begin{array}{l}\text { Comparison of characteristics with National Hospice } \\
\text { Organization guidelines }{ }^{66}\end{array}$ \\
\hline
\end{tabular}

$44 \%)$, and feeling nervous $(16,32 \%)$ were the most prevalent symptoms in the week before assessment. Twelve of 50 residents (24\%) scored at or above the possibly depressed cut point on the Geriatric Depression Scale.

Thirty-four of 50 residents $(68 \%)$ possessed adequate cognition to complete the values history; 1 refused to complete the medical interventions subsection. Responses to 2 basic life values questions (5-point Likert scale, 5 = extremely important, $1=$ not at all important) indicated a strong tendency to value maintaining the quality of remaining life $(3.9, \pm 0.8 \mathrm{SD})$ rather than prolonging life at less than current quality $(1.9, \pm 0.9 \mathrm{SD}, P<.001$ for difference in response distributions, Wilcoxon test). Most residents (20 of $33,61 \%$ ) wished to avoid cardiopulmonary resuscitation. Only a small percentage of residents expressed an unqualified wish to receive mechanical ventilation $(3 \%)$, total parenteral nutrition $(12 \%)$, or an enteral feeding tube $(21 \%)$. A greater percentage $(58 \%, 51 \%$, and $42 \%$, respectively), however, expressed willingness to receive these treatments for a brief (10 days or less) trial period. Thirty-six of 50 residents $(72 \%)$ had a durable power of attorney for health care, but only 4 residents $(8 \%)$ had a do-notresuscitate order. No resident met National Hospice Organization hospice eligibility criteria.

A mean of $5.3( \pm 2.0 \mathrm{SD})$ palliative care improvement recommendations per resident were generated from the baseline assessment at facility 1 and $4.8( \pm 2.2 \mathrm{SD})$ at facility 2. Table 3 summarizes the frequency of the various subcategories of recommendations.

\section{DISCUSSION}

\section{Preliminary Support for the TLC Model}

Our preliminary findings and those of others ${ }^{4,6,52}$ illustrate glaring deficits in the quality of palliative care for older persons. No subject in our study was terminally ill, and none was a candidate for hospice, yet all were approaching the end of life and had multiple unmet palliative care needs. These findings show a pressing need for a major paradigm shift in the way palliative care of elders is conceptualized and delivered. ${ }^{13}$ They also provide initial 


\section{Table 3. Palliative Care Improvement Recommendations for Elderly Residents of 2 Assisted Living Facilities ( $N=50$ )}

\begin{tabular}{lcc}
\hline Recommendation Category & No. & Percent \\
\hline Mobility problem, fall risk & 65 & 26 \\
Advance directive & 43 & 17 \\
Vision problem & 30 & 12 \\
Hearing problem & 28 & 11 \\
Symptoms (eg, pain) & 21 & 8 \\
Dementia, cognitive problem & 17 & 7 \\
Depression & 14 & 6 \\
Urinary incontinence & 7 & 3 \\
Miscellaneous & 29 & 11 \\
Total & 254 & 100 \\
\hline
\end{tabular}

* Recommendations were often addressed to more than 1 person (eg, resident family caregiver, physician) and could include more than 1 recommendation per category. For this analysis, a separate recommendation was recorded for each targeted person in such cases.

support for the TLC model as a promising framework for better meeting the palliative care needs of older patients. Until intervention evaluations like the PCAL study are completed, however, the impact of using the TLC framework on patient outcomes remains unclear. If the study results are favorable, future researchers might build upon the interventions we have outlined by including even greater emphasis on such important issues as bolstering patients' sense of dignity ${ }^{43,44}$ and self-efficacy ${ }^{67,68}$ and supporting family caregivers throughout the trajectory of chronic illness. ${ }^{26}$

\section{CONCLUSION}

It is clear that the prevailing model of palliative care is ill suited for application to older patients suffering from slowly progressive chronic illnesses. The TLC model provides a promising potential framework for designing interventions to address current palliative care shortfalls and improve both the quality of remaining life and process of dying for older persons and their loved ones. Given the high amount of conceptual overlap with already familiar tasks, such as chronic illness care coordination, primary care physicians appear well suited to assume the role of team leader for palliative care delivered within the TLC framework.

To read commentaries or to post a response to this article, see it online at http://www.annfammed.org/cgi/content/full/2/1//54.

Key words: Palliative care; residential facilities; aged, 80 and over; house calls; signs and symptoms

Submitted September 16, 2002; submitted, revised, January 17, 2003; accepted February 10, 2003.

Versions of this paper were presented in part at the RWJF GPFSP Annual Meeting, Ponte Vedra, Calif, December 4-6, 2002?
Funding support: Funded in part by a Robert Wood Johnson Foundation Generalist Physician Faculty Scholar Program (RWJF GPFSP) career development grant, No. 039176 (Dr. Jerant) and a RWJF Promoting Excellence in End of Life Care Program grant, No. 035490 (Dr. Meyers).

\section{References}

1. Lynn J, DeVries K, Arkes $\mathrm{H}$, et al. Ineffectiveness of the SUPPORT intervention: review of explanations. J Am Geriatr Soc. 2000;48 (Suppl 5):S206-S213.

2. Jacobs LG, Bonuck K, Burton W. Can "Palliative Care Reports" improve end-of-life care for hospitalized patients? J Pain Symptom Manage. 2002;24:299-311.

3. American Medical Association. Educating physicians on End of Llife Care Project (EPEC). EPEC Curriculum. Available at: http://www.amaassn.org/ama/pub/category/2910.html. Accessed December 1, 2002.

4. SUPPORT Investigators. A controlled trial to improve care for seriously ill hospitalized patients: the Study to Understand Prognoses and Preferences for Outcomes and Risks of Treatments (SUPPORT). JAMA. 1995;274:1591-1598

5. Liao S, Ferrell BA. Fatigue in an older population. J Am Geriatr Soc. 2000;48:426-430

6. Bernabei R, Gambassi G, Lapane K, et al. Management of pain in elderly patients with cancer. SAGE Study Group. Systematic assessment of geriatric drug use via epidemiology. JAMA. 1998; 279:1877-1882.

7. Fox $P L$, Raina $P$, Jadad AR. Prevalence and treatment of pain in older adults in nursing homes and other long-term care institutions: a systematic review. CMAJ. 1999;160:329-333.

8. Goodlin SJ, Jette AM, Lynn J, Wasson JH. Community physicians describe management issues for patients expected to live less than twelve months. J Palliat Care. 1998; 14:30-35.

9. Beekman ATF, Geerlings SW, Deeg DJH, et al. The natural history of late-life depression: a 6-year propsective study in the community. Arch Gen Psychiatry. 2002;59:605-611.

10. Bolmsjo I. Existential issues in palliative care--interviews with cancer patients. J Palliat Care. 2000;16:20-24.

11. Breitbart W. Spirituality and meaning in supportive care: spiritualityand meaning-centered group psychotherapy interventions in advanced cancer. Support Care Cancer. 2002;10:272-280.

12. Cleary JF, Carbone PP. Palliative medicine in the elderly. Cancer. 1997;80:1335-1347.

13. Introcaso D, Lynn J. Systems of care: future reform. J Palliat Med. $2002 ; 5: 255-257$.

14. Field MJ, Cassel CK, eds. Approaching Death: Improving Care at the End of Life. Washington, DC: National Academy Press; 1997.

15. Christakis NA, Escarce JJ. Survival of Medicare patients after enrollment in hospice programs. N Engl J Med. 1996;335:172-178.

16. Fox E, Landrum-McNiff K, Zhong Z, Dawson NV, Wu AW, Lynn J. Evaluation of prognostic criteria for determining hospice eligibility in patients with advanced lung, heart, or liver disease. SUPPORT Investigators. Study to Understand Prognoses and Preferences for Outcomes and Risks of Treatments. JAMA. 1999;282:1638-1645.

17. Lunney JR, Lynn J, Hogan C. Profiles of older Medicare decedents. J Am Geriatr Soc. 2002;50:1108-1112.

18. Christakis NA. Death Foretold : Prophecy and Prognosis in Medical Care. Chicago, III: University of Chicago; 1999:328.

19. The Bantam Medical Dictionary. New York, NY: Bantam; 1990.

20. McWhinney IR. A Textbook of Family Medicine. New York, NY: Oxford University Press; 1997.

21. Widder J, Glawischnig-Goschnik M. The concept of disease in pallia tive medicine. Med Health Care Philos. 2002;5:191-197.

22. George LK. Research design in end-of-life research: state of science. Gerontologist. 2002;42:86-98. 
23. Johnson PR. An analysis of dignity. Theoret Med Bioethics. 1998;19: 337-352.

24. Slomka J. The negotiation of death: clinical decision making at the end of life. Soc Sci Med. 1992;35:251-259.

25. Bronstein JM, Jones CA. Ethics, technology, and the high cost of dying: a public form. South Med J. 1986;79:1485-1488.

26. Hiltunen EF, Medich C, Chase S, Peterson L, Forrow L. Family decision making for end-of-life treatment: the SUPPORT nurse narratives. J Clin Ethics. 1999;10:126-134.

27. Back AL, Wallace JI, Starks HE, Pearlman RA. Physician-assisted suicide and euthanasia in Washington State. Patient requests and physician responses. JAMA. 1996;275:919-925.

28. Drought TS, Koenig BA. "Choice" in end-of-life decision making: researching fact or fiction? Gerontologist. 2002;42:114-128.

29. Liaschenko J. Faithful to the Good: Morality and Philosophy in Nursing [unpublished doctoral dissertation]. San Francisco: University of California, San Francisco, Calif; 1993.

30. Callahan D. A commentary - putting autonomy in its place: developing effective guidelines. Gerontologist. 2002;42:129-131.

31. Committee on Quality Health Care in America. Institute of Medicine. Crossing the Quality Chasm: A New Health System for the 21st Century. Washington, DC: National Academy Press; 2001:364.

32. Winker MA, Flanagin A. Caring for patients at the end of life: call for papers. JAMA. 1999;282:1965.

33. Lands RH. Comfort care: why wait until the end of life? South Med J. 1999;92:544.

34. World Health Organization (WHO). WHO definition of palliative care. Available at: http://www.who.int/dsa/justpub/cpl.htm. Accessed December 3, 2002.

35. Stange KC, Zyzanski SJ, Jaen CR, et al. Illuminating the "black box": a description of 4454 patient visits to 138 family physicians. J Fam Pract. 1998;46:377-389.

36. Robert Wood Johnson Foundation. Improving chronic illness care. Available at: http://improvingchroniccare.org. Accessed December 18 2002.

37. Frosch DL, Kaplan RM. Shared decision making in clinical medicine: past research and future directions. Am J Prev Med. 1999;17:285-294.

38. O'Connor AM, Stacey D, Rovner D, et al. Decision aids for people facing health treatment or screening decisions. Cochrane Database Syst Rev. 2001:CD001431

39. Center for Gerontology and Health Care Research. Brown University. TIME: toolkit of instruments to measure end of life care. Available at: http://www.chcr.brown.edu/pcoc/choosing.htm. Accessed December $18,2002$.

40. Sullivan MD, Kempen GI, Van Sonderen E, Ormel J. Models of health-related quality of life in a population of community-dwelling Dutch elderly. Qual Life Res. 2000;9:801-810.

41. Wilson IB, Cleary PD. Linking clinical variables with health-related quality of life: a conceptual model of patient outcomes. JAMA. 1995;273:59-65.

42. Stewart AL, Teno J, Patrick DL, Lynn J. The concept of quality of life of dying persons in the context of health care. J Pain Symptom Manage. 1999;17:93-108.

43. Chochinov HM. Dignity-conserving care: a new model for palliative care. JAMA. 2002; 287:2253-2260.

44. Chochinov HM, Hack T, McClement S, Kristjanson L, Harlos M. Dignity in the terminally ill: a developing empirical model. Soc Sci Med. 2002;54:433-443.

45. Reuben DB. Principles of geriatric assessment. In: Hazzard WR, Blass JP, Ettinger WH, Halter JB, Ouslander JG, eds. Principles and Practice of Geriatric Medicine and Gerontology. New York, NY: McGraw-Hill; 1999:467-481.

46. National Center for Assisted Living. Assisted living: independence, choice and dignity. Available at: http://www.ncal.org/about/alicd.pdf. Accessed May 15, 2002
47. American Health Care Association. Testimony of the National Center for Assisted Living presented to the Institute of Medicine Committee on Improving Quality in Long Term Care, March 12, 1998. Available at: http://www.ahca.org/brief/written.htm. Accessed May 13, 2002.

48. Bishop CE. Where are the missing elders? The decline in nursing home use, 1985 and 1995. Health Aff. (Millwood) 1999;18:146-155.

49. Zimmerman SS, Sloane PD, Eckert JK, eds. Assisted Living Needs, Practices, and Policies in Residential Care for the Elderly. Baltimore, MD: Johns Hopkins University Press; 2001.

50. Walter LC, Covinsky KE. Cancer screening in elderly patients: a framework for individualized decision making. JAMA. 2001;285:2750-2756.

51. Emmanuel LL, von Gunten CF, Ferris FD. Gaps in end-of-life care. Arch Fam Med. 2000;9:1176-1180.

52. Cartwright JC. Nursing homes and assisted living facilities as places for dying. Annu Rev Nurs Res. 2002;20:231-264.

53. Mezey M, Dubler NN, Mitty E, Brody AA. What impact do setting and transitions have on the quality of life at the end of life and the quality of the dying process? Gerontologist. 2002; 42:54-67.

54. Ware JE Jr, Gandek B, Kosinski M, et al. The equivalence of SF-36 summary health scores estimated using standard and country-specific algorithms in 10 countries: results from the IQOLA Project. International Quality of Life Assessment. J Clin Epidemiol. 1998;51: 1167-1170.

55. Ware JE Jr. The SF-36 Health Survey. Vol. 1999. Boston, Mass: The Health Institute, New England Medical Center; 1999.

56. Ware JE Jr, Kosinski M, Bayliss MS, McHorney CA, Rogers WH, Raczek A. Comparison of methods for the scoring and statistical analysis of SF-36 health profile and summary measures: summary of results from the Medical Outcomes Study. Med Care. 1995; 33: AS264-AS279.

57. Portenoy RK, Thaler HT, Kornblith AB, et al. The Memorial Symptom Assessment Scale: an instrument for the evaluation of symptom prevalence, characteristics, and distress. Eur J Cancer. 1994;30A: 1326-1336.

58. Sheikh JI, Yesavage JA. Geriatric Depression Scale (GDS): recent evidence and development of a shorter version. In: Clinical Gerontology: A Guide to Assessment and Intervention. New York, NY: The Haworth Press; 1986:165-173.

59. Folstein MF, Folstein SE, McHugh PR. "Mini-mental state." A practical method for grading the cognitive state of patients for the clinician. J Psychiatr Res. 1975; 12:189-198.

60. Rosen AK, Berlowitz DR, Anderson JJ, Ash AS, Kazis LE, Moskowitz MA. Functional status outcomes for assessment of quality in longterm care. Int J Qual Health Care. 1999;11:37-46.

61. Reuben DB, Siu AL. An objective measure of physical function in elderly outpatients. J Am Geriatr Soc. 1990;38:1105-1112.

62. Tinetti ME. Performance-oriented assessment of mobility problems in elderly patients. J Am Geriatr Soc. 1986;34:119-126.

63. Sherbourne CD, Stewart AL. The MOS social support survey. Soc SCi Med. 1991;32:705-714.

64. Fazel S, Hope T, Jacoby R. Assessment of competence to complete advance directives: validation of a patient centered approach. BMJ. 1999:318:493-497.

65. Doukas DJ, McCullough LB. The values history. The evaluation of the patient's values and advance directives. J Fam Pract. 1991;32: 145-153.

66. National Hospice Organization. Medical Guidelines for Determining Prognosis in Selected Non-Cancer Diseases. Arlington, Va: National Hospice Organization; 1996

67. Lorig KR, Sobel DS, Stewart AL, Brown BW, Bandura A, Ritter P. Evidence suggesting that a chronic disease self-management program can improve health status while reducing hospitalization: a randomized trial. Med Care. 1999;37:5-14.

68. Lorig KR, Ritter $P$, Stewart $A L$, et al. Chronic disease self-management program: 2-year health status and health care utilization outcomes. Med Care. 2001;39:1217-1223. 